\title{
UPAYA YANG DILAKUKAN DIABETISI YANG MENGGUNAKAN BPJS DALAM MENGENDALIKAN GULA DARAH
}

\author{
Maria Paulina Irma Susanti ${ }^{1}$ \\ ${ }^{1}$ Program Studi D3 Keperawatan Univeristas Harapan Bangsa \\ mariapaulina@uhb.ac.id
}

\begin{abstract}
Abstrak
Diabetes Mellitus merupakan penyakit metabolik yang berlangsung kronik di mana diabetisi tidak bisa memproduksi insulin dalam jumlah cukup atau tubuh tidak mampu menggunakan insulin secara efektif sehingga terjadi kelebihan gula di dalam darah. Pengendalian gula darah yang baik merupakan faktor kunci dalam mencegah terjadinya komplikasi. Hal ini dapat dicapai dengan pemberian obat antidiabetes, perubahan gaya hidup, maupun pengukuran kadar gula darah dan pemeriksaan laboratorium secara rutin. Meskipun penelitian tentang pengalaman diabetisi dalam mengendalikan gula darah sudah banyak, namun tetap ada kebutuhan untuk membedakan antara faktor dan proses yang terlibat dalam pengendalian gula darah lain seperti proses dalam penggunaan BPJS bagi diabetisi dan memperoleh gambaran pengalaman diabetisi tipe II yang menggunakan BPJS dalam mengendalikan gula darah. Penelitian ini merupakan penelitian kualitatif dengan 4 partisipan pengguna BPJS. Wawancara dianalisis secara tematik terstruktur dengan menggunakan pendekatan fenomenologi. Hasil penelitian yang didapatkan adalah tereksplorasinya upaya partisipan yang menggunakan BPJS dalam mengendalikan gula darah Sehingga dapat disimpulkan bahwa tema yang diperoleh dari hasil wawancara mendalam dapat menjawab pertanyaan penelitian yakni pengalaman diabetisi yang menggunakan BPJS dalam mengendalikan gula darah memerlukan upaya khusus berupa 5 pilar penatalaksanaan DM yang berkesinambungan agar pemanfaatan BPJS dapat dilaksanakan sebaik-baiknya. Disarankan pula bagi diabetisi agar lebih memahami alur rujukan/penggunaan BPJS sebagai dasar pengendalian gula darah yang maksimal.
\end{abstract}

Kata kunci: Upaya, diabetisi, pengendalian gula darah, BPJS

\begin{abstract}
Diabetes Mellitus is a chronic metabolic disease in which people with diabetes can not produce enough insulin or the body is unable to use insulin effectively resulting in excess sugar in the blood. Good blood sugar control is a key factor in preventing complications. This can be achieved by administering antidiabetic drugs, lifestyle changes, as well as regular blood glucose and laboratory measurements. Although research on the experience of people with diabetes in controlling blood sugar has been overwhelming, there remains a need to differentiate between factors and processes involved in other blood sugar controls such as the process in the use of BPJS for people with diabetes and gain experience of people with Type II diabetes who use BPJS in controlling blood sugar. This research is a qualitative research with 4 participants of BPJS users. The interviews were structured thematicly analyzed using a phenomenological approach. The result of the research is the exploration of the utilization of people with diabetes in controlling blood sugar, obstacles felt by people with BPJS in controlling Blood sugar, the attempts made by people with BPJS in controlling blood sugar. So it can be concluded that the theme obtained from the results of in-depth interviews can answer research questions that experience diabetisi using BPJS in controlling blood sugar require special efforts in the form of 5 pillars of sustainable DM so that BPJS utilization can be implemented as well as possible. It is also recommended for people with diabetes to better understand the flow of reference / use of BPJS as a basis for controlling blood sugar maximum.
\end{abstract}

Keywords: effort, people with diabetes, blood sugar control, BPJS 


\section{PENDAHULUAN}

Diabetes mellitus (DM) atau kencing manis, termasuk kategori penyakit degeneratif. Perubahan gaya hidup manusia dimasyarakat menjadi salah satu alasan penyakit DM semakin banyak diderita orang. Berbagai kemudahan hidup dan aneka jenis makanan yang mengandung gula berkadar tinggi dan lemak, menjadi kambing hitam meningkatnya jumlah penderita DM di Indonesia dan negara lain di dunia.

Tingginya risiko-risiko tersebut membuat PT. Askes (Persero) meluncurkan program pengelolaan penyakit DM Tipe II (PPDM Tipe II) yang bertujuan untuk menurunkan risiko komplikasi dan mencapai kualitas hidup yang baik dengan pemanfaatan biaya yang efektif dan rasional. BPJS Kesehatan mengintegrasikan program PPDM Tipe II menjadi salah satu program rutinnya. Program tersebut berganti nama menjadi Program Pengelolaan Penyakit Kronis (PROLANIS), (Fachmi, 2014).

Pada dasarnya diabetisi DM sudah memiliki kesadaran akan pengendalian gula darah, karena pada saat diabetisi memerlukan fasilitas kesehatan maka akan berusaha memanfaatkan layanan BPJS dan berupaya ke layanan kesehatan yang tertera di kartu kepesertaannya. Namun tidak sedikit diabetisi yang mengeluhkan beberapa kesulitan dan hambatan dalam pengendalian gula darah.

Dampak pada pengendalian kesehatannya dalam hal ini gula darah diabetisi DM yang tidak bisa dikontrol oleh petugas kesehatan, kemungkinan juga faktor-faktor yang berpengaruh selain misalnya dengan penggunaan fasilitas BPJS adalah masih banyak diabetisi yang dirugikan karena mendapatkan kesulitan pelayanan kesehatan di RS, diabetisi sudah berusaha datang pagi agar mendapat antrian namun karena keterbatasan jumlah yang diterima, terpaksa pulang tanpa pelayanan yang tidak sesuai dengan fasilitas yang diberikan tersebut. Penelitian yang mengeksplorasi pengalaman diabetisi dalam mengendalikan gula darah dengan menggunakan BPJS belum ada di Kabupaten Banyumas. 
Viva Medika: Jurnal Kesehatan, Kebidanan, dan Keperawatan, 11 (02), Maret 2019

Maria Paulina Irma Susanti (Upaya Yang Dilakukan Diabetisi Yang Menggunakan Bpjs Dalam Mengendalikan Gula Darah)

Berdasarkan fenomena dan kajian diatas maka untuk memahami pengalaman Diabetisi yang menggunakan BPJS dalam pengendalian gula darah, maka rumusan masalah dan tujuan dalam studi ini adalah lebih ditekankan pada "bagaimana upaya diabetisi yang menggunakan BPJS dalam mengendalikan gula darah di RSUD Prof. Dr. Margono Soekarjo Purwokerto?"

\section{METODOLOGI}

Desain dan pengaturan studi deskriptif kualitatif ini melibatkan wawancara semi terstruktur dengan 4 partisipan yang menggunakan BPJS. Penelitian ini diambil dalam rentang waktu bulan april - Agustus 2017. Persetujuan etis diperoleh di setiap lokasi intervensi yaitu di RSUD Prof. Dr. Margono Soekarjo Purwokerto dan dari universitas Muhammadiyah Jakarta yang berpartisipasi. Penelitian ini telah meneliti Upaya diabetisi dalam mengendalikan gula darah dengan menggunakan BPJS. Peneliti memilih fenomenologi deskriptif, yaitu penelitian yang menggambarkan fenomena mengenai pemanfaatan
BPJS dalam mengelola gula darah dan pengendaliannya sebagai pengalaman hidup. Peneliti memahami keunikan individu dan arti pengalaman diabetisi dalam memengendalikan gula darah dengan menggunakan BPJS.

Metode penelitian ini berupaya mengeksplorasi, menganalisis dan menjelaskan fenomena dari pengalaman secara luas, terperinci dan mendalam. Terdapat empat langkah dalam proses penelitian fenomenologi deskriptif, yaitu: bracketing, intuisi, analisis dan interpretasi (Polit \& Beck, 2015). Bracketing adalah suatu proses mengurung, atau menyimpan berbagai pengetahuan, asumsi, dan keyakinan yang ada pada peneliti tentang fenomena yang akan diteliti. Langkah selanjutnya intuisi, yaitu peneliti secara keseluruhan memahami dan mengenali fenomena yang akan diteliti. Pada tahap ini peneliti mulai memahami arah dan tema pengalaman yang diceritakan oleh partisipan. Langkah ketiga yaitu analisis, peneliti melakukan analisis dan mengidentifikasi data atau informasi yang ditemukan. Kegiatan 
Viva Medika: Jurnal Kesehatan, Kebidanan, dan Keperawatan, 11 (02), Maret 2019

Maria Paulina Irma Susanti (Upaya Yang Dilakukan Diabetisi Yang Menggunakan Bpjs Dalam Mengendalikan Gula Darah)

analisis ini dibagi menjadi beberapa tahapan yaitu mengumpulkan dan menganalisis data, melakukan proses koding, proses kategorisasi, proses tematik, dan menuliskan pola hubungan antar tema ke dalam bentuk narasi. Langkah terakhir yaitu interpretasi, peneliti menuliskan interpretasinya dalam bentuk hasilhasil temuan disertai dengan pembahasan mengenai fenomena yang diteliti. Hal ini dilakukan untuk memberikan informasi kepada pembaca mengenai hasil akhir penelitian yang dilakukan.

\section{Rekruitmen Partisipan}

Populasi yang dilibatkan dalam penelitian ini adalah seluruh diabetisi tipe II yang mempunyai BPJS yang menjalani perawatan di RSUD Prof. Dr. Margono Soekarjo Purwokerto. Kriteria inklusi dalam penelitian ini yaitu diabetisi yang menggunakan BPJS di unit rawat jalan dan juga mengikuti program PROLANIS. Adapun kriteria sampel dalam penelitian ini yaitu:

(1) Diabetisi tipe II yang menggunakan BPJS, (2) Diabetisi dengan lama menderita DM lebih dari 6 bulan sehingga diharapkan partisipan sudah memiliki pengalaman dalam menggunakan dan memanfaatkan layanan BPJS untuk mengendalikan gula darah dengan justifikasi pada penelitian Hasyim 2014 dalam Harismayati 2017 mengatakan bahwa pasien dengan lama menderita DM lebih dari 6 bulan sudah memiliki pengalaman dalam mengendalikan kadar glukosa darah. (3) Bersedia menjadi partisipan hal ini lakukan berdasarkan prinsip etika penelitian yaitu self determinant atau partisipan berhak untuk ikut atau tidak dalam penelitian sehingga penelitian ini tidak mengandung unsur paksaan berdasarkan etika penelitian.

(4) Mampu berkomunikasi dengan baik.

(5) Partisipan tidak dalam kondisi yang lemah atau kronik agar tidak mengganggu partisipan selama proses penyembuhan dan istirahat. Teknik pengambilan sampel dalam penelitian ini menggunakan teknik purposive sampling yaitu mengambil sampel dari anggota populasi yang memenuhi kriteria sesuai dengan kriteria inklusi, (Notoatmojo, 2010). 
Viva Medika: Jurnal Kesehatan, Kebidanan, dan Keperawatan, 11 (02), Maret 2019

Maria Paulina Irma Susanti (Upaya Yang Dilakukan Diabetisi Yang Menggunakan Bpjs Dalam Mengendalikan Gula Darah)

Panduan wawancara semi terstruktur dikembangkan berdasarkan metodologi yang dipublikasikan dan uji coba intervensi. Proses berulang untuk meninjau, memandu dan memperbaiki panduan wawancara dilakukan, melibatkan pembimbing sebagai tim peneliti dengan pengalaman partisipan dalam pengendalian gula darah. Pertanyaan disusun dalam lima domain utama: 1). Respon perilaku, 2). Diet, 3). Obatobatan, 4). Management emosi, 5). Stretegi. Pertanyaan dan petunjuk untuk setiap domain ditunjukkan pada Tabel 1.

Wawancara digunakan dengan panduan wawancara semi terstruktur yang memberikan arahan bagi pewawancara. Pertanyaan langsung diajukan saat percakapan. Wawancara berlangsung kira-kira 45-60 menit atau sesuai kesepakatan dan direkam secara digital dan kemudian ditranskripsi untuk dianalisis.

Tabel 1 : Wawancara semi terstruktur dan pertanyaan

\begin{tabular}{|c|c|}
\hline Domain & $\begin{array}{l}\text { Contoh pertanyaan } \\
\text { petunjuknya }\end{array}$ \\
\hline $\begin{array}{l}\text { Persepsi Diabetisi } \\
\text { tentang program } \\
\text { BPJS untuk DM }\end{array}$ & $\begin{array}{l}\text { - Apa yang partisipan } \\
\text { ketahui tentang program } \\
\text { BPJS untuk DM? }\end{array}$ \\
\hline
\end{tabular}

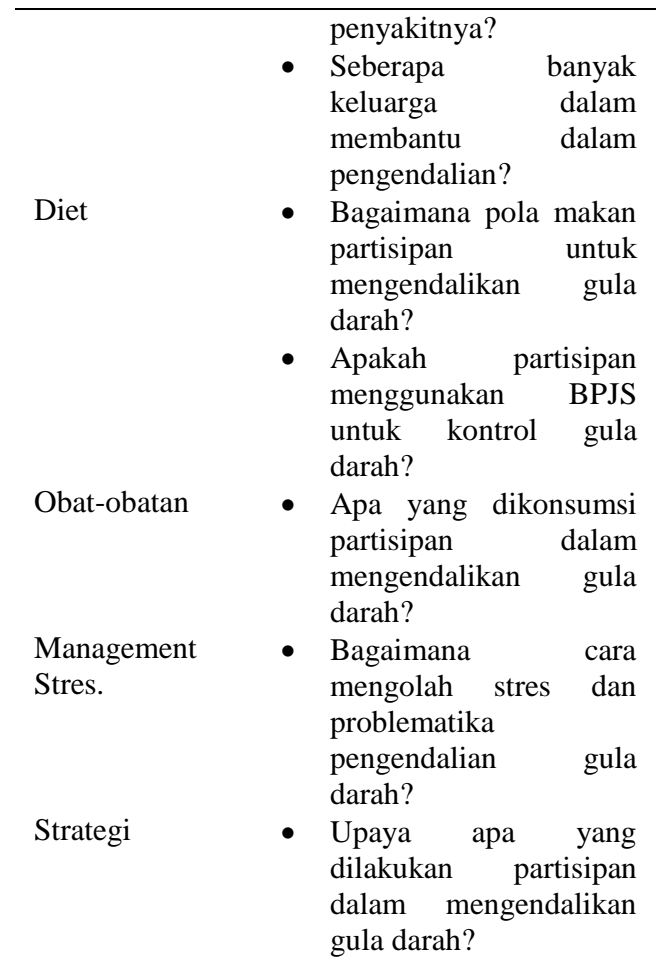

Alat bantu pengumpulan data pada penelitian ini adalah (1) Peneliti sendiri sebagai pemandu wawancara. (2) Panduan wawancara semi terstruktur yang berisikan pertanyaan terbuka untuk menggali tujuan penelitian. (3) Catatan lapangan (field notes) yang digunakan untuk mencatat hasil pengamatan peneliti selama wawancara. (4) Memo digunakan untuk mencatat informasi hasil observasi peneliti diluar selama melakukan wawancara mendalam. (5) Voice recorder yang digunakan untuk merekam hasil wawancara langsung. 
Viva Medika: Jurnal Kesehatan, Kebidanan, dan Keperawatan, 11 (02), Maret 2019

Maria Paulina Irma Susanti (Upaya Yang Dilakukan Diabetisi Yang Menggunakan Bpjs Dalam

Mengendalikan Gula Darah)

\section{Analisa Data}

Analisis tematik digunakan untuk menganalisis data wawancara semi terstruktur. Transkrip wawancara dibaca dan dibaca ulang; Kode dikembangkan berdasarkan pernyataan verbatim peserta; Melakukan peer debriefing dan hasil lapangan mengenai tindakan informan setelah dideskripsikan selanjutnya didiskusikan dengan pembimbing dan teman sejawat Kepercayaan (Trustworthiness) terhadap temuan ditanggung oleh: (a) mendiskusikan temuan di antara tim peneliti untuk memastikan data ditafsirkan sesuai dengan kata kunci, kategori, sub tema dan tema yang muncul (credibility) dan (b) menggunakan purposive sampling untuk memastikan representasi partisipan yang luas (transferability).

\section{HASIL DAN PEMBAHASAN}

Karakteristik data demografi partisipan disajikan dalam tabel 2

\section{Tabel 2: Karakteristik Partisipan}

\begin{tabular}{ccccccc}
\hline No & $\begin{array}{c}\text { Kode } \\
\text { Parti } \\
\text { sipan }\end{array}$ & Umur & $\begin{array}{c}\text { Jenis } \\
\text { Kela } \\
\text { min }\end{array}$ & $\begin{array}{c}\text { Pendi } \\
\text { dikan } \\
\text { Terak } \\
\text { hir }\end{array}$ & $\begin{array}{c}\text { Pekerja } \\
\text { an }\end{array}$ & $\begin{array}{c}\text { Lama } \\
\text { DM }\end{array}$ \\
\hline 1 & P1 & 60 & P & SMP & IRT & 1 tahun \\
2 & P2 & 42 & P & SD & ART & 13 tahun \\
3 & P3 & 50 & P & SD & Peda & 13 tahun \\
4 & P4 & 45 & P & SD & ART & 13 tahun \\
\hline
\end{tabular}

\section{Analisis Tematik}

Bagian ini menjelaskan secara mendetail dan terperinci berbagai tema yang teridentifikasi dari hasil pengumpulan data. Setelah melalui proses analisa data dengan menggunakan content analysis yang dikembangkan Colazzi, sebanyak empat tema telah teridentifikasi. Kelima tema ini merepresentasikan makna inti dari upaya diabetisi tipe II dalam mengendalikan gula darah dengan menggunakan BPJS. Kelima tema tersebut yaitu: Persepsi Diabetisi tentang program BPJS untuk DM, Diet, Obat-obatan, managemen stres dan streategi

\section{Keabsahan data}

Penelitian kualitatif atau kualitas data pada penelitian ditentukan dari keabsahan data yang dihasilkan. Data yang dihasilkan harus mengandung unsur keterpercayaan, keautentikan, dan kebenaran terhadap temuan yang dihasilkan dari penelitian yang dilakukan. Menurut Afiyanti dan Rachmawati (2014), terdapat empat istilah yang digunakan untuk 
Viva Medika: Jurnal Kesehatan, Kebidanan, dan Keperawatan, 11 (02), Maret 2019

Maria Paulina Irma Susanti (Upaya Yang Dilakukan Diabetisi Yang Menggunakan Bpjs Dalam Mengendalikan Gula Darah)

menyatakan keabsahan data pada penelitian kualitatif, yaitu:

1. Kredibilitas, cara yang akan dilakukan untuk mencapai kredibilitas pada penelitian ini dengan melibatkan partisipan mulai dari pengumpulan data hingga analisis data. Peneliti melakukan kredibilitas dengan cara mengembalikan transkrip wawancara dan tema sementara kepada partisipan untuk memvalidasi hasil verbatim bersama dengan peneliti. Jika partisipan telah menyetujui bahwa transkrip data dan tema sudah sesuai dengan apa yang telah disampaikan partisipan, maka data penelitian dianggap sudah memenuhi kredibiltas. Selain itu data penelitian akan didiskusikan kepada teman sejawat untuk diteliti apakah hasil penelitian sudah memenuhi kredibilitas, (Afiyanti dan Rachmawati, 2014).

2. Transferabilitas, yang dilakukan untuk mencapai transferabilitas yaitu peneliti akan membuat laporan dengan uraian yang jelas, terperinci, sistematis, serta dapat dipercaya mulai dari deskripsi partisipan, lokasi penelitian, prosedur pengumpulan data serta hasil penelitian
3. Dependabilitas, tehnik yang dilakukan untuk mencapai dependabilitas pada penelitian ini dengan inquiry audit, yaitu proses telaah data penelitian yang dilakukan oleh penelaah eksternal.

4. Konfirmabilitas, konfirmabilitas yang dilakukan pada penelitian ini yaitu melakukan konfirmasi kepada partisipan dan pembimbing setelah proses analisis data selesai dilakukan.

Tabel 2: Tema

\begin{tabular}{|c|c|c|c|}
\hline $\begin{array}{l}\text { Kata } \\
\text { Kunci }\end{array}$ & Kategori & Sub-tema & Tema \\
\hline Prolanis & & $\begin{array}{c}\text { (Program } \\
\text { BPJS) }\end{array}$ & $\begin{array}{l}\text { Persepsi } \\
\text { Diabetisi } \\
\text { tentang } \\
\text { program } \\
\text { BPJS untuk } \\
\text { DM }\end{array}$ \\
\hline
\end{tabular}

\begin{tabular}{|c|c|c|c|}
\hline Gratis & \multicolumn{3}{|c|}{ Fasilitas } \\
\hline Nasi, sayur & $\begin{array}{c}\text { Jenis } \\
\text { makanan }\end{array}$ & & \\
\hline $2-3 x$ & $\begin{array}{l}\text { Frekuensi } \\
\text { makan } \\
\text { sehari }\end{array}$ & $\begin{array}{c}3 \mathrm{~J} \\
\text { (jumlah, } \\
\text { jam ,jenis) }\end{array}$ & Diet \\
\hline $\begin{array}{l}\text { Pagi siang } \\
\text { sore }\end{array}$ & waktu & & \\
\hline Obat Gula & Obat & & \\
\hline Obat & $\begin{array}{c}\text { oral/injeksi } \\
\text { Obat- } \\
\text { obatan }\end{array}$ & $\begin{array}{c}\text { Farmakolo } \\
\text { gi }\end{array}$ & Obat-obatan \\
\hline Pasrah & $\begin{array}{l}\text { Respon } \\
\text { perilaku }\end{array}$ & $\begin{array}{l}\text { Koping } \\
\text { positif }\end{array}$ & \\
\hline $\begin{array}{l}\text { Sholat } \\
\text { Suport }\end{array}$ & $\begin{array}{c}\text { Dukungan } \\
\text { keluarga } \\
\text { dan tenaga } \\
\text { kesehatan }\end{array}$ & & $\begin{array}{c}\text { Managemen } \\
\text { stres yang } \\
\text { dilakukan } \\
\text { diabetisi }\end{array}$ \\
\hline $\begin{array}{l}\text { Kurangi } \\
\text { stres }\end{array}$ & $\begin{array}{c}\begin{array}{c}\text { Hindari } \\
\text { stress }\end{array} \\
\end{array}$ & $\begin{array}{c}\text { Manageme } \\
\text { n emosi }\end{array}$ & \\
\hline $\begin{array}{l}\text { Kontrol } \\
\text { Rutin }\end{array}$ & & Follow up & Strategi \\
\hline Tensi, & & Check up & \\
\hline
\end{tabular}


Viva Medika: Jurnal Kesehatan, Kebidanan, dan Keperawatan, 11 (02), Maret 2019

Maria Paulina Irma Susanti (Upaya Yang Dilakukan Diabetisi Yang Menggunakan Bpjs Dalam Mengendalikan Gula Darah)

\begin{tabular}{lc} 
timbang, & \\
cek gula & \\
Sebulan & Keberlanjut \\
sekali & an \\
Berangkat & Strategi \\
lebih Pagi & \\
\hline
\end{tabular}

\section{Upaya yang dilakukan diabetisi yang menggunakan BPJS dalam mengendalikan gula darah.}

Dari hasil wawancara diketahui bahwa dari pengalaman-pengalaman partisipan, teridentifikasi aspek-aspek pengalaman yang berkorelasi positif terhadap pencapaian kontrol glukosa darah. Berdasarkan pemaparan partisipan, faktor-faktor yang teridentifikasi mendukung pengendalian gula darah partisipan meliputi respon psikologis, kebutuhan spiritual, interaksi sosial, jenis makanan, frekuensi makan, porsi makan, obat, jenis aktivitas, frekuensi aktivitas serta yang terakhir yaitu cek gula darah dan pandangan hidup positif.Intervensi Farmakologis dan terapi farmakologis diberikan bersama dengan pengaturan makan dan latihan jasmani (gaya hidup sehat). Terapi farmakologis terdiri dari obat oral dan bentuk suntikan. Pemahaman tentang obat-obatan yang dirasakan partisipan tercermin dalam pernyataan berikut:
"Yaa ada yang jam 6 sebelum makan sebelum sarapan, ada yang jam 7 setelah sarapan,...” (P1)

"Obat vormin, sehari 3 kali..." (P2)

"saya pakai obat, makan di atur. Makan makanan dari diabet yaa di kendalikan laah, makan metvormin dan gliben.."(P3)

"Satu bulan sekali udah 2 bulan ini. Sehari 3 kali. Pertama 4 unit, terus 6 unit.." (P4)

Faktor aktivitas fisik juga berperan dalam meningkatkan pengendalian terhadap gula darah. Hal ini nampak pada empat partisipan yang menyatakan bahwa mereka selalu berupaya untuk berolahraga setiap ada kesempatan. Komitmen partisipan untuk selalu melakukan aktivitas fisik dapat dilihat pada kalimat-kalimat berikut:

"pagi pagi kan berangkatnya pagi jam 6 dari rumah disana olahraga dulu" (P2)

"Di sana saya pertama, udah olahraga. Dah olahraga, yang dikasih ini apa.." (P3)

Olahraga DM, Itu senam koran bu untuk kaki” (P4)

Pada dasarnya diabetisi sudah memiliki kesadaran akan pengendalian gula darah berikut pada saat diabetisi tersebut memerlukan fasilitas kesehatan maka akan berusaha memanfaatkan layanan BPJS dan berupaya ke layanan kesehatan yang tertera di kartu kepesertaannya, kategori edukasi 
Viva Medika: Jurnal Kesehatan, Kebidanan, dan Keperawatan, 11 (02), Maret 2019

Maria Paulina Irma Susanti (Upaya Yang Dilakukan Diabetisi Yang Menggunakan Bpjs Dalam Mengendalikan Gula Darah)

tergambar dari pernyataan dibawah ini:

"Nah saya suka itu malah ada kumpulan-kumpulan kaya itu jadi saya tambah pengalaman dan pengetahuan......." (P1)

"dapat penjelasan apa yang boleh dan tidak boleh. Disitu saya merasa semangat kalau datang di kumpulan itu karena ilmu bertambah.."(P2)

"Terus dijelasin sama dokter. Dikasih saran..” (P4)

"saya kalo ke dr Gizi selalu diberikan informasi,.....” (P3)

Salah satu pilar penatalaksanaan DM adalah Follow up yang merupakan cara partisipan mengelola penyakitnya karena dari kerinduan akan berkunjung di pelayanan kesehatan gula darah senantiasa terkontrol:

"Prolanis itu sebulan sekali ada kumpulan,.”.(P4)

Saya kumpulannya di puskesmas sebulan sekali" (P1)

"Ya sering setiap bulan" (P2)

"Dua, kalo periksan di prolanis itu harus rutin. "(P3)

Pemahaman General check up yang merupakan inti dari pemeriksaan DM disambut baik partisipant, hal ini sangat tercermin dalam wawancara berikut ini: "nanti dapat ini apa keterangan dari dokter kan diperiksa dulu diambil darahnya..." (P1)

"tensi, timbang BB, senam. Iya, ya diambil darahnya gitu dicek terus di periksa dokter. Nanti diperiksa dokter selesai tunggu 2 jam diambil lagi darahnya" (P2)

"Itu penimbangan lansia, Di sana malah diperiksa, (P3)

"ditimbang, tensi, cek gula terus diperiksa dokter. Puasa dulu dari jam $10 \mathrm{mlm}$, terus nanti dicek. Habis dicek disuruh makan, habis 2 jam makan dicek lagi. “(P4)

Program yang diluncurkan pemerintah berupa PROLANIS sudah menjadi harapan tersendiri bagi partisipan, pemanfaatan kepersertaan pada BPJS dapat meningkatkan derajat kesehatan manusia setinggitingginya, wawancara dibawah ini menggambarkan betapa senangnya partisipan dalam menggunakan BPJS dalam pengendalian gula darah:

"Ya bermanfaat bagi saya ya. Ada keterangan lanjutan gitu, "Iya pertolongan dari pemerintah juga hehe, gratis" (PI)

"Gratis, Engga bayar." (P2)

“Gratis..Sama sekali malah" (P3)

"Ga. Dulu juga pas opname 4 hari pake itu ga bayar sama sekali" (P4)

Respon psikologis terlihat dalam wawancara berikut :

"Kalo sekarang si udah pada tau, Ya nangis. Kasian. Harus hati-hati gitu." (P1) 
Viva Medika: Jurnal Kesehatan, Kebidanan, dan Keperawatan, 11 (02), Maret 2019

Maria Paulina Irma Susanti (Upaya Yang Dilakukan Diabetisi Yang Menggunakan Bpjs Dalam Mengendalikan Gula Darah)

"ya saya hanya pasrah, ibu saya kena stroke dan bisa sembuh walau tidak sempurna saya yakin Alloh kasih yang terbaik pada saya...” (P2)

"Engga saya malah mintaaaaaa... seperti itu minta pokoknya minta, Ikhtiar, Pasrah bu..(P3)

Wawancara berikut menggambarkan kebutuhan spiritual seluruh partisipan kepada Tuhan YME, dengan berdamai dengan sang pencipta lewat senandung panjatan-panjatan do'a dapat memberikan sisi positif terhadap kesembuhan tersendiri:

"Kemudian saya selalu minta pada Tuhan pas saya sholat... “(P2) "Do'a ajalah pengin sembuh, inget sama yang kuasa yg kasih hidup yang kasih makan." (P1)

"Ya.. saya minta.. sama Tuhan, ya Aloh. saya dikasih... kesembuhan Seperti biasa.. kayak gitu.. kalau udah.. sehabis sholat" (P3) (P4)

Terkait interaksi dengan perawat, dokter dan petugas kesehatan lainnya, keluarga, suami, anak, teman maupun saudara, partisipan menyatakan bahwa perawat dalam bekerja sudah cukup baik keluarga juga ikut serta memberikan dukungan positif pada saat partisipan membutuhkan support. Hal ini nampak dari pernyataanpernyataan partisipan sebagai berikut:
"Terus suami tau banget malah ya? Malah dukung membantu memberikan dukungan, Ya dokter yang laki-laki disana tadi, Iya baik semua." (Pl)

"Saya lakukan sebisa saya semampu saya dalam melakukan kegiatan sehari-hari,.. “(P2)

Pengaturan diet dan obat-obatan terlihat dalam wawancara berikut :

"ada jatah makan yang ini nih ga habis dok, lauknya segini banyaknya paling bandeng separuh, nanti nasinya ya $3 / 4$ lah jatah dari sini saya kurangi 1/4.." (P3)

"Yang nasi si 3 kali, ya saya usahain ya 3 kali. Kalo dulu dulu kan sukanya 2 kali, udah malam udah ga mau makan dengan sendirinya ga mau makan gitu. (P1)

"Ya menghindari makanan yang manis, makan nasi dikurangi, Ya paling nasi sayur nasi sayur, Ya ga bisa pantangan. Paling mengurangi, sehari 2 kali" (P2),

$Y a$ obat gula, Obat vormin, sehari 3 kali. "(P2)

"Obat ya dari sini (RSUD Margono) “( $(P 1)$

"Ya makan nasi pake sayur, minum teh tawar atau air bening, kopi kalo lagi pengin. Dua kali. Pagi sama malam. Satu centong, ga banyak..(P4)

"Satu bulan sekali udah 2 bulan ini. Sehari 3 kali. Pertama 4 unit, terus 6 unit " (P4)

Pandangan hidup positif berupa penerimaan terhadap penyakitnya merupakan hal positif yang dapat memberiakan reaksi positif terhadap 
Viva Medika: Jurnal Kesehatan, Kebidanan, dan Keperawatan, 11 (02), Maret 2019

Maria Paulina Irma Susanti (Upaya Yang Dilakukan Diabetisi Yang Menggunakan Bpjs Dalam Mengendalikan Gula Darah)

tubuh agar tetap menilai produktif hidup dengan DM

"Ya kerja apa gitu, biar ga keliatan sakit banget, Tuhan yang beri sakit Tuhan yang beri sembuh dokter sebagai pengantar..." (P4)

"saya lakukan sebisa saya semampu saya..... (P2)

"saya kena diabet, tapi anggap saja gak punya penyakit. Tapi saya berusaha berobat.... (P3)

Beberapa kekompakan para partisipan yang tergambar dibawah ini menunjukan suatu upaya yang dilakukan untuk mengatasi beberapa hambatan dari pengendalian gula darah dengan menggunakan BPJS:

"Datang aja yang pagi agar dapat antrian awal..." (P1)

"Jam 6 pagi dari rumah..."(P2) "saya ingin cepat ya saya ingin berangkatnya cepat sekarang saya kalo berangkat setengah lima Ambil antrian" (P3)

"Biasanya komunikasi sama yang lain siapa yang berangkat cepet biar ambilin no antrinya...." (P4)

\section{PEMBAHASAN}

Tujuan yang paling utama dalam penelitian ini adalah untuk menggali secara mendalam upaya diabetisi dalam mengendalikan gula darah dengan menggunakan BPJS. Interview semi tematik terstruktur dilakukan untuk memperoleh pemahaman tentang pengalaman partisipan sampai ke tingkat makna inti/essence dari pengalaman tersebut dari perspektif partisipan sebagai individu yang secara langsung mengalaminya. Secara khusus penelitian ini dirancang untuk mengungkap berbagai dimensi pengalaman partisipan dalam mengontrol glukosa darah secara holistik, meliputi dimensi persepsi, psikologis, sosial, dan spiritual. Lebih jauh lagi dalam penelitian juga dikaji bagaimana pengalaman partisipan memanfaatkan kepesertaanya menggunakan BPJS dalam mengendalikan gula darahnya.

Hasil penelitian ini juga menunjukkan bahwa pasien DM yang tidak teratur melakukan kontrol kadar gula darah puasa meski setiap 3 bulan sekali lebih banyak mempunyai nilai kadar gula darah buruk tercatat hampir setengah jumlah responden. Penelitian yang dilakukan oleh Soegiarto pada tahun 2013 menyatakan peningkatan kadar gula darah puasa terjadi bukan sematamata hanya karena keteraturan terhadap jadwal kontrol saja, melainkan masih terdapat faktor lain 
Viva Medika: Jurnal Kesehatan, Kebidanan, dan Keperawatan, 11 (02), Maret 2019

Maria Paulina Irma Susanti (Upaya Yang Dilakukan Diabetisi Yang Menggunakan Bpjs Dalam Mengendalikan Gula Darah)

seperti faktor usia yang menyebabkan kadar gula darah meningkat, (Soegiarto, 2013).

Respon Psikologis individu bervariasi, dengan berdamai dengan sang pencipta lewat senandung panjatan-panjatan do'a dapat memberikan sisi positif terhadap kesembuhan.Temuan tentang pengaruh positif dari integritas spiritual pada penelitian ini identik dengan beberapa penelitian yang pernah dilakukan. Partisipan empat menyatakan bahwa salah satu alasannya untuk berupaya mengendalikan pola makannya adalah agar dapat lebih lama beribadah dan mengabdi kepada Tuhan. Hal ini selaras dengan hasil penelitian Salehi (2012) yang menyatakan bahwa keinginan untuk terus beribadah terbukti meningkatkan semangat partisipan untuk bangkit dari depresi akibat amputasi dan memperbaiki gaya hidupnya agar tidak sampai timbul luka yang baru. Pengalaman partisipan 2 yang sempat merasa putus asa sehingga tidak lagi memerdulikan pola makannya, kemudian berubah setelah membaca peringatan dalam kitab suci juga terbukti relevan dengan hasil penelitian Doolitle pada tahun 2004.

Diet, pada prinsipnya, pada pasien DM diperlukan makanan yang seimbang (karbohidrat, protein, lemak, serat, vitamin, dan mineral) dan sesuai dengan kebutuhan kalori pasien. Selain itu, pada pasien DM juga diperlukan pengaturan jadwal makan, jenis dan jumlah makanan ( 3 J ). Penyandang DM perlu diberikan penekanan mengenai pentingnya keteraturan jadwal makan, jenis dan jumlah makanan, terutama pada mereka yang menggunakan obat penurun glukosa darah atau insulin.

Obat-obatan ini akan selalu diperlukan oleh pasien DM untuk mengontrol kadar gula dalam darah. Obat-obatan DM bersifat individual artinya jenis dan dosis yang diberikan oleh dokterhanya berlaku untuk satu pasien. Kepatuhan dalam mengkonsumsi obat merupakan aspek utama dalam penanganan penyakitpenyakit kronis. Memperhatikan kondisi tersebut di atas, kepatuhan dalam mengkonsumsi obat harian menjadi focus dalam mencapai derajat kesehatan pasien, dalam hal ini perilaku ini dapat dilihat dari 
Viva Medika: Jurnal Kesehatan, Kebidanan, dan Keperawatan, 11 (02), Maret 2019

Maria Paulina Irma Susanti (Upaya Yang Dilakukan Diabetisi Yang Menggunakan Bpjs Dalam Mengendalikan Gula Darah)

sejauhmana pasien mengikuti atau mentaati perencanaan pengobatan yang telah disepakati oleh pasien dan profesional medis untuk menghasilkan sasaran-sasaran terapiutik (Frain, dkk., 2009).

Pandangan hidup positif berupa penerimaan terhadap penyakitnya merupakan hal positif yang dapat memberiakan reaksi positif terhadap tubuh agar tetap menilai produktif hidup dengan DM. Pasien dengan tingkat motivasi yang baik terbukti mampu menyusun target yang harus dicapai dari perawatan, serta dapat melakukan tindakan-tindakan yang menunjang pencapaian target tersebut, (Delamater, 2006 dalam Ahmad, 2012).

Strategi yang dilalukan partisipan untuk menunjukan suatu upaya yang dilakukan untuk mengatasi beberapa hambatan dari pengendalian gula darah dengan menggunakan BPJS partisipan mengatakan cara yang tepat untuk mendapatkan no antrian dalam pendaftaran di RS bervariasi dan unik, itu adalah salah satu upaya yang dapat dilakukan dalam rangka mengatasi hambatan yang pernah dibahas dalam tema sebelumnya.
Kekompakan yang dialami atau dilakukan partisipan dengan temantemannya sesama diabetisi menjadi kunci yang menopang salah satu support sistem berupa dukungan teman sehingga dapat memberikan efek yang positif dalam pengendalian gula darah.

\section{SIMPULAN}

Berdasarkan hasil penelitian dapat disimpulkan upaya diabetisi yang menggunakan BPJS dalam mengendalikan gula darahnya adalah sebagai berikut:

Makna pengalaman diabetisi dalam mengendalikan gula darahnya diwakili oleh empat tema, yaitu:

1. Persepsi Diabetisi tentang program BPJS untuk DM

2. Diet

3. Obat-obatan

4. Managemen stres yang dilakukan diabetisi

5. Strategi

\section{DAFTAR PUSTAKA}

Afiyanti \& Rachmawati, 2014. Metodologi Penelitian Kualitatif Dalam Riset Keperawatan: Jakarta. PT Raja Grafindo Persada 
Viva Medika: Jurnal Kesehatan, Kebidanan, dan Keperawatan, 11 (02), Maret 2019

Maria Paulina Irma Susanti (Upaya Yang Dilakukan Diabetisi Yang Menggunakan Bpjs Dalam Mengendalikan Gula Darah)

Ahmad, H. W. 2012. Pengalaman Klien Diabetes Mellitus Tipe 2 Dalam Mengontrol Glukosa Darah Secara Mandiri di Kota Depok. Tesis UI. Depok

Creswell, John W. 2016. Researh Design (Pendekatan Metode Kualitatif, Kuantitatif dan Campuran) Edisi 4. Yogyakarta. Pustaka Pelajar.

Analisis Biaya penyakit Diabetes Mellitus, COST ANALYSIS OF DIABETES MELLITUS. Artikel Penelitian http://jmpf.farmasi.ugm.ac.id/i ndex.php/1/article/view/30 diunduh 27 Februari 2017

Harismayanti. 2017. Studi fenomenologi: Pengalaman Diabetisi Dalam Mengendalikan Kadar Glukosa Darah di Wilayah Kerja Puskemas Limboto Kabupaten Gorontalo

Hidayat, AA. (2008). Riset Keperawatan dan Teknik Penulisan Ilmiah. Jakarta: Salemba Medika.

Hidayat, A. 2012.Riset Keperawatan dan Teknik Penulisan Ilmiah. Jakarta: Salemba Medika.

2009.Metode Penelitian Keperawatan \& Teknik Analisis Data. Jakarta: Salemba Medika.

Idris, Fachmi. 2014. Pengintegrasian Program Preventif Penyakit Diabetes Melitus Tipe 2 PT Askes (Persero) ke Badan Penyelenggara Jaminan
Kesehatan Sosial Kesehatan (BPJS Kesehatan), Artikel Penelitian

Laurentia, M. 2009. Faktor Yang Berhubungan Dengan Pengendalian Gula Darah Pada Penderita DM di Wilayah Perkotaan Indonesia. BPPKes Jakarta.

Maisyaroh, A., Ratnawati, R., \& Rachmawati, S. D. (2015). Studi Fenomenologi Kebutuhan Dan Hambatan Perawat Dalam Pelaksanaan Resusitasi Pada Kegawatan Neonatus Prematur Di Ruang Neonatus Rsd Dr. Haryoto

Media Internal Bpjs Kesehatan Edisi 32 Tahun 2016. 2016. INFO BPJS: Kenaikan Iuran Untuk Pemantapan Pelayanan. BPJS Kesehatan. Buletin BPJS

Safitri IN. Kepatuhan penderita diabetes melitus tipe II ditinjau dari lokus of control. J Ilm Psikol Terap. 2013;1:18.

Shelley, R.,Elizabeth. M et all. 2016. Nurses's Perceptions of a Pressure Ulcer Prevention Care Bundle: a qualitative descriptive study. research article Journal International

Smeltzer, S.C.C.,Bare, B.G., Hinkle, J.L. and Cheever,K.H. eds., 2010. Brunner and Suddarth's textbook of medical surgical nursing (Vol 1). Lippincott Williams \& Wilkins

Soegiarto RB. Kepatuhan kontrol dengan tingkat kadar gula 
Viva Medika: Jurnal Kesehatan, Kebidanan, dan Keperawatan, 11 (02), Maret 2019

Maria Paulina Irma Susanti (Upaya Yang Dilakukan Diabetisi Yang Menggunakan Bpjs Dalam

Mengendalikan Gula Darah)

darah pasien diabetes melitus di Rumah Sakit Baptis Kediri. Stikes. 2012;5(2):213-22

'Sugiyono, 2002. Metode Penelitian Kuantitatif dan Kualitatif Dan R \& D, Bandung : Alfabeta

Sugiyono. 2007. Statistik Untuk Penelitian. Bandung: Alfabeta.

Soegondo. 2011. Penatalaksanaan Diabetes Mellitus Terpadu. Jakarta: Pusat Diabetes dan Lipid RSUPN Dr. Cipto Mangunkusumo dan FKUI, bekerjasama dengan WHO dan Kementrian Kesehatan RI

Vera, T., A.J. M Rattu., Ch. R Tilaar. Vera Tombokan A. J. M Rattu Ch. R. Tilaar, 2015. Faktor-faktor yang Berhubungan dengan Kepatuhan Berobat Pasien Diabetes Melitus pada Praktek Dokter Keluarga di Kota Tomohon. Artikel Penelitian

World Health Organization (WHO), 2016. Global status report on noncomminicable deseases 2014. World Health Organization (WHO) 